\title{
Women and water management in times of climate change: participatory and inclusive processes
}

\author{
Patricia Figueiredo, Patricia E. Perkins* \\ Faculty of Environmental Studies, York University, Toronto M3J 1P3, Canada
}

\section{A R T I C L E I N F O}

\section{Article history:}

Received 18 July 2011

Received in revised form

17 February 2012

Accepted 18 February 2012

Available online 7 March 2012

\section{Keywords:}

Climate justice

Gender

Watershed management

Climate change

Equity

Public participation

Civil society

Women

Community-based environmental

education

Civil society engagement

Resilience

Bottom-up climate change adaptation

\begin{abstract}
A B S T R A C T
This paper focuses on community engagement, and particularly the inclusion of women, in water management as a response to climate change. Addressing water-related problems is central to climate change adaptation, and civil society, marginalized populations and women, in particular, must be involved. This is for both moral and pragmatic reasons: not only are the marginalized the first and worst affected by extreme weather events, but they also possess local ecological, social and political knowledge which can inform and contribute significantly to climate change adaptation strategies. Because of their social roles and position worldwide, women are greatly affected by water scarcity and flooding, and tend to be gravely impacted by poor water management, yet they face great difficulties in participating effectively in governance bodies. Sustainable long-term management of water resources in the face of climate change requires the participation of women, who possess knowledge of effective social technologies for coping with and adapting to climate change. Community-based environmental education is therefore required in order to expand the equitable involvement of women in water-related climate change adaptation activities and policy development. Environmental non-governmental organizations worldwide, working on shoestring budgets at the local level, are developing a range of methods to organize, raise consciousness and confidence, and help local activists create successful climate defense programs. This paper discusses South-North initiatives and models for community-based environmental and climate change education which are using the democratic opening provided by watershed-based governance structures to broaden grassroots participation, especially of women, in political processes. We outline the activities and results of two international projects: the Sister Watersheds project, with Brazilian and Canadian partners (2002-2008); and a Climate Change Adaptation in Africa project with partners in Canada, Kenya, Mozambique, and South Africa (2010-2012).
\end{abstract}

(c) 2012 Published by Elsevier Ltd.

\section{Introduction: gender equity and climate change}

Socially vulnerable people, and women in particular, are disproportionately affected by global climate change because of their geographic location and gendered socioeconomic roles, yet they are least equipped to deal with its impacts due to their disadvantaged economic and political position.

This paper argues that women have special contributions to make towards climate change adaptation because of gendered differences in positional knowledge of ecological and water-related conditions. Although women play multiple roles at home as well as in local communities, they tend to be largely underrepresented, and

\footnotetext{
* Corresponding author. Tel.: +1 416736 2100x22632; fax: +1 4167365679.

E-mail addresses: pattyf@yorku.ca (P. Figueiredo), esperk@yorku.ca (P.E. Perkins).
}

in many cases excluded, from environmental decision-making processes, especially in the context of climate change adaptation. The dominant climate change narrative often presents women as "victims, rather than as agents capable of contributing to solutions" (Terry, 2009: 3), but women possess valuable local ecological and social knowledge derived from their traditional gender roles. In African countries, as in most developing countries, women are the principal managers of natural resources, which they and their families rely on for their livelihoods. "In addition to their prominence in agriculture and in much of the informal sector, women bear the brunt of domestic tasks: processing food crops, providing water and firewood, and caring for the elderly and the sick" (Blackden and Wodon, 2006: 2). More and more, climate change and climate variability are negatively impacting women's everyday lives and their ability to perform these daily tasks. Climate variability (e.g. prolonged droughts and intense floods) and environmental degradation will continue to compromise agriculture, 
affecting the livelihoods and wellbeing of rural women and their families in developing countries; the United Nations estimates that by 2025, two-thirds of arable land in Africa will disappear (BiedCharreton, 2008).

According to the Fourth Assessment Report of the Intergovernmental Panel on Climate Change (IPCC), "climate change will aggravate the water stress currently faced by some [African] countries, while some countries that currently do not experience water stress will become at risk of water stress" (IPCC, 2007). Many women in developing countries travel great distances to find water, so climate change will make their daily lives even more difficult. "As gendered work and family responsibilities make poor women the main cleaners and caregivers, poor women are the ones most affected by water issues" (Moraes and Perkins, 2009).

Climate change is already altering "the distribution of precipitation, and intensity and frequency of precipitation events could potentially exacerbate both flooding and water scarcity" (Anisfeld, 2010: 102). Urban dwellers living in flood-prone areas are likely to experience more intense and longer floods and consequential landslides. "Developing countries are vulnerable to extremes of normal climatic variability, and climate change is likely to increase the frequency and magnitude of some extreme weather events and disasters" (Mirza, 2003). These disproportionately impact women, who typically posses fewer financial and social resources than men and are therefore more vulnerable to the adverse impacts of climate change. For example, a recent study found that

"natural disasters (and their subsequent impact) on average kill more women than men or kill women at an earlier age than men. Biological and physiological differences between the sexes are unlikely to explain large-scale gender differences in mortality rates. Social norms and role behavior provide some further explanation, but what is likely to matter most is the everyday socio-economic status of women" (Neumayer and Plümper, 2007).

This indicates that women's vulnerability to climate change and variability is strongly influenced by their socioeconomic status and gender roles, which undermine their ability to cope with and adapt to climate change. One way to build women's adaptive capacity is to address their vulnerability by improving their socioeconomic status and access to resources. The IPCC Third Assessment Report (TAR) describes adaptive capacity as "the ability of a system to adjust to climate change (including climate variability and extremes) to moderate potential damages, to take advantage of opportunities, or to cope with the consequences."

Acknowledging and addressing the many significant interactions between climate change and gender inequalities is fundamental for the development of climate policy and adaptation strategies that are effective and gender-just and which do not further aggravate existing inequalities. "Interventions that create greater awareness and understanding of the complex links between gender equality and the environment can help to build the capacity of the poor, especially poor women, to adapt to the impacts of, and take action on climate change." (CIDA, 2002: 3)

Education and involvement of women in formal decisionmaking processes can strengthen their adaptive capacity. This also furthers climate justice, which involves the principles of “'avoiding dangerous climate change,' 'forward-looking responsibility,' 'putting the most vulnerable first,' and 'fair participation of all”" (Paavola et al., 2006).

Many grassroots climate change approaches focus on laying the groundwork for broader political participation, which can facilitate long-term self-directed community-based climate change defense strategies (Ensor and Berger, 2009). These locally based approaches promote capacity building, community empowerment, social inclusiveness and participation. There is an extensive literature on the theoretical and practical grounding for such participatory processes (Sagoff, 1998; Holland, 1997; van den Hove, 2000; Faucheux and Hue, 2001; Wilson and Howarth, 2002; Perkins, 2003). Public consultation and broad civil society involvement in decision-making is generally recognized as desirable in resource management, public policy, and development planning (Gregory and Slovic, 1997; De Marchi et al., 2000; Kapoor, 2008; Kothari, 2001).

The "bottom-up" approach "focuses on the social vulnerability of individuals or groups to both existing climate variability and future climate change. This approach also analyses past experiences of how communities have coped with extreme events as a guide to future thresholds and adaptive behaviour" (Meyer et al., 1998). In contrast to "top-down" approaches, the bottom-up approach encourages communities to use local skills and knowledge to identify their vulnerabilities to climate change and variability and develop adaptation strategies that are tailored to their needs. This self-directed approach combined with capacity-building efforts is likely to enhance a community's adaptive capacity and reduce its vulnerability. Building women's adaptive capacity, in particular, besides assisting individual women to become politically active and develop their leadership, can contribute to enhancing the adaptive capacity of the communities where they live, given the significant roles they play (e.g. food production) within their communities (Table 1).

"(Adaptation) activities should simultaneously reduce the impacts of potential climate change and improve the well-being of households or communities in the short term-for example through addressing poor housing, degraded soils or the inequitable distribution of resources. These approaches to adaptation are in essence vulnerability reduction measures, and can be classified as no-regrets strategies-meeting climate change adaptation goals while fulfilling broader development ends even if climate change predictions do not play out" (Ensor and Berger, 2009: 16).

Community-based education and organizing are fundamental to creating the conditions for local knowledge to be shared and utilized, through equitable democratic participation. Building inclusive governance structures and strengthening the role of civil society, especially women, in water governance are essential components for addressing vulnerability and fostering resilience and sustainability in urban centres as well as rural areas. According to the Intergovernmental Panel on Climate Change, "adaptation is shown to be successful and sustainable when linked to effective governance systems, civil and political rights and literacy" (Parry et al., 2007). Non-governmental organizations in the Global South and in marginalized areas of the North have expertise on how to do this which is potentially shareable and may be relevant in other places.

Table 1

Characteristics of a bottom-up approach to climate change adaptation.

1. Is inclusive and participatory

2. Starts at the community leve

3. "Takes account of existing adaptation and coping mechanisms at the local level" (Lim and Spanger-Siegfried, 2004)

4. "Employs the experience and knowledge of community members to characterize pertinent conditions, community sensitivities, adaptive strategies, and decision-making process related to adaptive capacity or resilience" (Smit and Wandel, 2006: 258).

5. "In contrast to 'top-down' methods, (implicitly recognizes) adaptive capacity" (Dessai et al., 2004: 13)

6. Prioritizes local subsistence and basic needs

7. Attempts to improve the situation of the most vulnerable first

8. Seeks synergies in socio-political-economic strategies to bring communities together in response to climate change 
This paper outlines the activities and results of two international projects: the Sister Watersheds project with Canadian and Brazilian partners (2002-2008), and a Climate Change Adaptation in Africa project with partners in Canada, Kenya, Mozambique, and South Africa (2010-2012). Both projects have demonstrated the wide applicability of local-level efforts in vulnerable communities in Toronto and in African and Brazilian cities to address equity challenges by developing strategies and materials for increasing the knowledge, interest and engagement of local residents on waterrelated and climate change issues, focussing on low-income neighbourhoods, and in particular on women and youth.

Community-based environmental education initiatives which are relevant and interesting for local residents and increase their job opportunities, knowledge of watershed issues, understanding of basic political and ecological principles, and confidence to express and act on their views can serve as the basis of a climate change intervention approach which is progressive, constructive and democratic. This, in turn, increases the resilience and sustainability of watershed and climate change decision-making processes. It also lays the groundwork for community organizing and extension of the environmental education activities to larger constituencies in local areas affected by climate change.

In the following sections, we discuss some specifics of this climate justice approach, and its relevance for community-based environmental action in Canada, in relation to our work with international partners on two projects in Brazil and Africa.

\section{Sister watersheds: education for equitable water governance in Brazil and Canada}

Deforestation and environmental degradation, rural-urban migration and continued urbanization exacerbate Brazil's vulnerability to climate change. "In semi-arid northeastern Brazil, prolonged droughts have provoked rural-urban migration of subsistence farmers, while increases in precipitation and extreme rainfall events have been observed in Southern Brazil" (IPCC, 2007). In North and Northeastern Brazil, the poor generally still lack access to adequate sanitation and clean water. Women, more specifically those living in informal settlements, are among the worst affected by this structural inequality.

While Brazil has a progressive watershed management system-requiring participation by civil society representatives on watershed committees-low-income people and women in particular are underrepresented. Watershed committees are formed "so that water users can collectively help to decide issues of allocation, infrastructure and regulation at the watershed level" (Hinchcliffe et al., 1999; Perkins, 2004). However, social norms and perceptions, and illiteracy may impact women's ability to participate in these committees. Special training is strongly needed to enable women to participate actively and effectively by articulating their views, insights and perspectives on local climate change and water-related challenges. Issues such as how to elicit and motivate effective public involvement among economically stressed groups in civil society, how to easily convey and discuss complex ecological issues in public workshops, and how to build bridges between disadvantaged local communities and public officials at the watershed level, know no boundaries: this is a global problem.

The Sister Watersheds project (2002-2008) linked universities and NGOs in Canada and Brazil in developing strategies and materials for increasing the knowledge, interest and engagement of local residents on water-related issues, focussing on low-income neighbourhoods in São Paulo and Toronto, and in particular on lowincome women. This $\$ 1.3$ million project-funded by the Canadian International Development Agency (CIDA) through the Association of Universities and Colleges of Canada-combined student exchanges, research, community engagement, and "capacity building" in local communities and nearby universities. Its novel conceptualization and design were developed by progressive Brazilian environmental educators Dr. Marcos Sorrentino (a professor at the University of São Paulo who was subsequently appointed director of environmental education in the Brazilian federal Ministry of the Environment) and Larissa da Costa of the Ecoar Institute for Citizenship (ECOAR), who subsequently became environmental education director at the World Wildlife Fund in Brasilia. The project's design evolved throughout its implementation by organizers at ECOAR, a leading environmental education NGO based in São Paulo, Brazil and York University in Toronto, Canada.

Addressing the lack of participation by and inclusion of civil society representatives, especially women, in water sector governance, which of course has parallels in every country including Canada, was a primary objective of the Sister Watersheds project. The project developed and tested training programs by conducting workshops led by its local NGO partners with more than 1450 participants, approximately two-thirds of them women, and by partnering with other community organizations to present content on topics related to environmental education and watershed management. For example, staff from ECOAR contacted groups of elementary school teachers, public health extension agents, and other community-based workers and provided in-service training for them about water and health, basic ecology, and public policy questions related to water in their local communities. The various training programs were shaped and modified to be specifically appropriate for groups of women, children, youth, health agents, school groups, teachers, film/culture/music/arts organizations, and Agenda 21/environmental education groups. The workshops focused on water management, environmental education, community development, and democratic participation, with particular emphasis on gender and socioeconomic equity. The methodologies, techniques, and materials developed for these workshops and training programs-made freely available to other organizations through publications and websites-contributed to the capacity of project partner organizations and individual staff members and students to continue related work on watershed policy issues into the future.

The curriculum materials and techniques developed by the project were tested and fine-tuned in more than 220 workshops designed and led by project staff, student interns, and university exchange students in three watersheds-two in Brazil and one in Canada-where university campuses are located near low-income residential areas. All of the Brazilian workshop participants in Brazil's watershed committees, as civil society representatives/organizers. The outreach materials developed by the project include an illustrated Manual on Participatory Methodologies for Community Development containing a set of workshop activities and background materials for participatory community environmental education programs and training sessions focussing on water and gender equity issues; an illustrated guide with practical exercises focussing on urban agroecology; a full-colour socio-environmental atlas which brings together ecological, hydrological and social information about one local watershed in a series of interactive maps; a video about the history and environment of one of the watersheds; a publication outlining Agenda 21 activities in schools; and several blogs and websites with materials and discussionstarters on watershed topics, as well as a book and many journal articles, masters' papers, and other academic publications contributing to the literature on participatory watershed education in Brazil and in Canada (Sister Watersheds, 2008).

The community environmental perception surveys conducted by the project in each of the Brazilian watersheds established a database of information on public priorities and views on 
watershed issues. The socio-environmental atlas gathered and made available in one place a wide range of information on ecological, hydrological, social and political circumstances in the watershed-information which proved very useful to public officials and watershed committee members in understanding the watershed as a whole. The nearly 1500 participants in workshops conducted by the project gained familiarity and experience with water-related issues and their own ability to influence water management and policy through watershed committee structures, community organizing, community arts, and other means.

This project helped both its university and NGO participants to bridge the gap between academic and community-based methods of environmental education. Graduate exchange students studied and contributed to local training programs; faculty members wrote about the theoretical and practical benefits of public participation in watershed management; NGOs supervised students who received academic credit for their community-organizing work; professors led local watershed governance structures; innovative methods for environmental education were shared internationally. This collaboration allowed new perspectives on water management to evolve, with benefits for all participants' training/education programs. The University of São Paulo, York University and ECOAR developed dozens of new partnerships with other community organizations as a result of this project. Students, both in Brazil and in Canada, played a crucial role in developing the linkages between academic institutions and community-based NGOs. Both locally and internationally, students sought out community organizations for their research and field experiences, and shared the results of their work with both academic and non-academic audiences. The student exchanges of this project thus fuelled its interdisciplinary and educational bridging contributions.

The methods and approach of the Sister Watersheds project proved to be entirely applicable to climate change education and organizing in Canada as well as in Brazil. Beginning in the summer of 2006, using some of the workshop ideas and materials generated in Brazil, several teams of York University graduate assistants and volunteers conducted a series of environmental education workshops with young people from the Jane/Finch and Black Creek West neighbourhoods, which border York University, as part of summercamp and after-school programs in a variety of local community centres and other venues. This programming contributed environmental content to the summer experiences of these young people, and gave York University students practical opportunities to test their environmental education skills. The materials and workshop ideas generated for these summer programs served as the basis for Sister Watersheds graduate assistants' participation with a local community development organization, Doorsteps Neighbourhood Services, in after-school programs for children aged 8-13. ECOAR organizers visited the Doorsteps programs, and ongoing links developed, which enriched programming ideas, materials, and techniques on both sides. We found there are far more international commonalities than differences in doing community-based environmental education with youth.

Most of the neighbourhood youth workshop participants were girls, since the boys tended to gravitate towards sport-centred programs, and parents in the area, largely new Canadians, were more concerned to have their daughters enrolled in organized programming. When the environmental education included pulling on hip-waders and taking samples of the water in Black Creek for benthic invertebrate monitoring, however, the boys were very eager participants! The students and staff leaders of the workshops were mainly women, by a ratio of more than 4 to 1 .

One particular contribution of the York/Black Creek "sister" has been the evolving art-based "Black Creek Storytelling Parade," a participatory performance walk held periodically that follows the route of stormwater from York's campus to the banks of Black Creek, using different storytellers from neighbourhood organizations to recount the history of the natural and built environment. Various creative strategies-costumes, sidewalk chalk, and percussion instruments-are employed to engage the audience. The content of the stories includes natural, cultural and political dimensions: the First Nations land claim covering the entire City of Toronto, the Haudenesaunee village buried under electric lines just south of the campus, how the creek acts as a cultural divide between two very distinct neighbourhoods, and local ecological restoration efforts as showcased by young students at a nearby elementary school. The Black Creek Storytelling Parade, which was developed by York graduate students in the area of Community Arts Practice, shakes up conventional understandings of nature by emphasizing social, cultural and political stories-tales often left untold in the city's official chronicles. This helps build an ecological imagination-the capacity to imagine how we could be living in such a way that people, plants and animals thrive in ecologically sustainable and socially just futures. It does so by sparking dialogue and dreams for a restored creek-restored not just in terms of greenery and cleanliness, but also in terms of social and cultural importance.

When the Sister Watersheds project began in 2002, there were no community organizations in the Jane-Finch/Black Creek West neighbourhood with environmental programming or a climate change focus. In 2008, the Jane/Finch Community and Family Centre, a local NGO, began applying for funding to develop jobs training for local residents in the area of energy retrofit evaluation, community garden development, and other "green jobs." The Green Change Project they created has been phenomenally successful, won awards, and is now training its third cohort of Green Change Agents-local residents who gain skills, references, confidence and a forward-looking perspective which greatly increases their employment opportunities (add Green Change website ref www.greenxchange.ca). York University alumni, students and faculty are involved in developing the curriculum, teaching workshop modules, and serving on the advisory board for the Green Change Project - which has lately morphed into the GreenXChange project, acknowledging the many partnerships it has generated. At its gala fundraiser in March 2011, keynote speaker Majora Carter overviewed many similar initiatives in low-income neighbourhoods throughout the U.S. and other countries, where community development, green job creation, and ecological restoration are combining to produce powerful synergies. The GreenXChange Project was developed and is led by community activists including women, and about two-thirds of the Green Change Agents trained so far are women.

As part of a new international research/linkage project (see below), two York University graduate students have written overviews of climate change and water-related equity issues in Toronto, in preparation for their exchange visits to African cities to study similar questions there. One of these Toronto studies is a history of the Green Change Project, which organizers will use on their website and in future grant proposals; the other student is writing an overview of the impacts of climate change and adaptation policies in Toronto through an equity/climate justice lens.

The importance of community watershed awareness and water infrastructure in times of climate change was underscored for the York University and Jane/Finch neighbourhood in August 2005, when a torrential thunderstorm caused massive flooding. Black Creek, normally a slow trickle, became a roaring torrent that overwhelmed and washed out the 1950's-era culvert built to carry it under Finch Avenue, a four-lane arterial roadway in northwest Toronto. Over a period of several hours, the creek carved a chasm about $50 \mathrm{~m}$ wide and $10 \mathrm{~m}$ deep. Repairs, including a new bridge for Finch Avenue, cost more than $\$ 3$ million and took nearly six months 
to be completed. During this time, commuter traffic and city buses were diverted through the York University campus, causing major disruptions for the university and local residents alike.

This was a graphic example of how extreme weather events-which are increasing in frequency due to climate change-in conjunction with ageing infrastructure and urban sprawl (including campus development) and increasing rapid rainfall runoff, can have costly and traumatic effects on everyone in the watershed. Social knowledge at the watershed level greatly facilitates adaptation to such new realities.

\section{Climate change and urban water governance in Africa}

According to the Intergovernmental Panel on Climate Change (IPCC), "Africa is one of the most vulnerable continents to climate change and climate variability. This vulnerability is exacerbated by existing developmental challenges such as endemic poverty, limited access to capital, ecosystem degradation, and complex disasters and conflicts" (IPCC, 2007). Income inequality in South Africa, Mozambique, and Kenya is among the largest in the world; in all three countries, equity struggles related to water are growing in social, political and ecological significance, which is both a symptom and a cause of urban vulnerabilities related to climate change.

In Mozambique, climate change is causing coastal erosion and periodic flooding along scenic coastal roadways; saltwater intrusion, wind erosion, and desertification in urban food-producing areas; flooding in coastal slum areas; degradation of water quality in wells and potable water scarcity; and the destruction of mangroves and threats to the locally important shrimp fishery. There are clear signs that the sea level is rising, with concomitant expensive coastal management problems in Maputo municipality. On three offshore islands mangroves are disappearing, water quality is declining, and desertification and erosion are increasing (UN Habitat, 2010, p. 2). The United Nations Habitat Cities in Climate Change Initiative, which has begun a pilot project in Maputo, emphasizes local government capacity building, policy dialogue, climate change awareness, public education, and developing coordination mechanisms between all levels of government as priorities to help address these risks. Mozambique's national water law (1991) considers all water as state-owned, to be governed by the state for the benefit of the population, with water access for people, sustainability, and stakeholder participation as priorities. Four water basin committees have been established in Mozambique on the same general model as in Brazil. To make this participatory model more effective, the largest need is for capacity building and community organizing to deepen and strengthen civil society's involvement in water governance.

As in Mozambique, South Africa is implementing watershed committees or "catchment management agencies" (CMAs) to decentralize decision-making and create a framework for integrating the needs of all stakeholders in water governance. Durban's municipal government has already developed a local climate change adaptation strategy; like Maputo, Durban faces coastal inundation and storm surges related to sea level rise, hotter temperatures and heat waves, changed rainfall and storm patterns, slum flooding and reduced drinking water supplies due to climate change. Local policy initiatives rely for effectiveness on awareness and capacity regarding climate change risks and adaptive responses in civil society. Environmental education and confidence-building through capacity-raising are recognized as crucial needs in this process; for example, the Inkomati CMA has initiated outreach programs targeting rural poor, emerging farmers, women and youth. Grounded participatory research leading to accessible public education and responsive community-based programs with civil society organizations are needed to help address these significant water governance challenges. This type of action research is well developed in Durban, partly due to the work of the Centre for Civil Society at the University of KwaZulu-Natal and its partner NGOs.

In Nairobi, severe infrastructure needs are being exacerbated by water supply fluctuations and slum flooding related to climate change. Just as in Maputo and Durban, environmental awareness and education leading to more equitable governance processes are required. As noted by the Kenyan delegation to the 2007 UN conference on climate change in Nairobi, Kenya's adaptation priorities include education, good governance, human resources development and training, institutional capacity building and management change, public finance improvement, and better national resources management. Nairobi, one of the largest and most complex cities in the world, provides a challenging arena for participatory governance research.

Democratic mediation of equity conflicts related to water, and sustainable long-term management of water resources in the face of climate change, requires public participation, in particular by low-income marginalized women - the experts.

"Strengthening the role of civil society in water sector governance towards climate change adaptation in African cities-Durban, Maputo, Nairobi" is a three-year project we are engaged in, along with African partners in the three cities. Its goal is to improve watershed governance for climate change adaptation and enhance resilience and adaptive capacity of vulnerable and marginalized groups, especially women. This project, which started in 2010, is supported by the Climate Change Adaptation in Africa (CCAA) program-a joint initiative of Canada's International Development Research Centre (IDRC) and the United Kingdom's Department for International Development (DFID). Like the earlier Sister Watersheds Project, this project's methodology includes collaboration between students, NGOs and academics as well as community-based research and environmental education. Project partners based in universities and several NGOs in Kenya, Mozambique and South Africa are working together to achieve the following objectives:

- To characterize the institutional framework for urban water governance in the three cities, and explain how different actors within this framework cope with climate change and variability;

- To identify and test viable alternatives for enhancing civil society's role towards adaptation to climate change and variability by vulnerable groups (e.g. by developing education, training and awareness programmes); and

- To share widely the knowledge generated for potential adoption by other cities in Africa.

The project is being implemented by the following communitybased NGOs in Africa: Kilimanjaro Initiative (KI) and Kenya Debt Relief Network (KENDREN) in Nairobi; Women, Gender and Development (MuGeDe) and Justiça Ambiental (JA) in Maputo; and Umphilo waManzi (Water for Life) and the South Durban Community Environmental Alliance (SDCEA) in Durban. The University of Nairobi (Nairobi), Eduardo Mondlane University (Maputo), and the Centre for Civil Society at the University of KwaZulu-Natal (Durban) provide academic research coordination and student supervision for this project.

The project focuses on low-income areas of each city, as these tend to be most severely affected by periodic flooding and other climate change impacts. Furthermore, residents of low-income areas often lack the ability to protect themselves against the impacts of extreme weather events. The capacity-building aspects of this project include training and research sponsorship for students and faculty in the partner universities; support for 
community-based research, workshops in low-income communities and secondary schools, curriculum and materials development, and skills development within the partner NGOs; training of environmental educators and organizers; contributions to the pool of experienced and qualified community workers in each country; strengthening of all the partner institutions' capabilities to carry out international projects; and contributions to the international literature and professional knowledge concerning water issues, environmental education techniques, and community organizing for improved civil society involvement in governance. The networks being built extend from local and community-based linkages through regional and national-level policy groupings to international academic and policy networks on civil society, watershed management, and governance.

The political process of policy development and implementation depends on the interchange between civil society groups, researchers generating information on current realities, and government. This project attempts to challenge the conventional notion that only educational institutions "produce" knowledge. Understanding community needs and what helps particular civil society groups to see and act to strengthen their role in democratic governance, for example, is something in which community organizations and NGOs have eminent expertise. This collaborative approach, also known as participatory action research (PAR) is broadly defined as "research by, with, and for people affected by a particular problem, which takes place in collaboration with academic researchers. It seeks to democratize knowledge production and foster opportunities for empowerment by those involved" (Kindon et al., 2008).

One objective of this project is to demonstrate how partnerships between academics and non-academics can be very stimulating and effective. This type of partnership encourages and allows the partner NGOs to reflect on and analyse their activities and to document "learning" more systematically than they are often able to do, by bringing student researchers into the NGOs as collaborators/interns. The partnership also encourages universities to be more pragmatic about teaching and research, and to "field-test" approaches towards community organization, equity, and capacity building. Students committed to the project's goals of fomenting participatory engagement by local people in municipal water decision-making are given practical opportunities to develop their skills, as a way of hastening each city's climate change preparedness. This project aims to contribute to the integration and meaningful participation of women in formal decision-making processes, as well as to build their adaptive capacity and increase their resilience and ability to cope with climate change.

Specific examples of how climate change responses combine well with gender-aware community organizing, all of which are now underway through this project (Table 2), include the following:

- The Kilimanjaro Initiative (KI), a youth-focused $\mathrm{NGO}$, is currently upgrading a sports field in Nairobi's Kibera slum, on the banks of the Nairobi River, which will prevent housing from being flooded during extreme weather events. In addition, KI organizes community forums on sustainable water management and environmental education, as well as community and river clean-ups. Young women's leadership is central to their organizing.

- In Durban, women activists from Umphilo waManzi and the South Durban Community Environmental Alliance are coordinating "learning journeys" where government officials visit low-income neighbourhoods to hear about local women's experiences with flooding, sanitation and other types of climate change stresses, which helps them to bring these views into policy discourse.
Table 2

Participatory and inclusive processes.

Ways of bringing women into water management, starting at

the community level

- Community mapping: residents collectively draw maps of important water features in the neighbourhood and how extreme weather affects them; then discuss.

- Photo-voice: community members photograph local scenes significant to them, in relation to climate change effects, and discuss/share with government officials.

- Water dialogues: local residents discuss specific water issues with government officials, in forums facilitated by civil society organizations.

- Learning journeys: community groups run tours of key water/ environment-related features in the area for local residents, government officials and visitors.

- Water walks / storytelling parades: using waterways as a focus, local residents and visitors tour stream beds and floodplains, stopping for special presentations on local history, wildlife, food production, music, community assets, etc.

- Collective storytelling workshops: community groups use selected 'props' to spark creativity as they compose a joint story about the local watershed, sharing personal memories.

- Green change agents training: NGOs run workshops for local youth in certificate programs helping develop job-related skills such as environmental building audits, green construction, green roof landscaping, floodplain rehabilitation, etc.

- Community-based water monitoring: community groups work with government authorities to monitor pollution, biostatus, and flooding/ drought in local waterways.

- Water conflict mediation training: special NGO-run training programs address water conflicts (e.g. over standpipe access, fugitive emissions of pollutants, riparian rights, etc.) through skills training and information on how to access government supports.

- Academic-activist linkage building: students get academic credit for internships with local civil society organizations, and help document their work and write funding applications; professors research and disseminate the methods and accomplishments of community groups.

- Sports field and league development: CSOs and youth groups organize social/recreational activities to make use of floodplains and advocate for their preservation as open, public space.

- Dry sanitation: CSOs facilitate the distribution and education/ advocacy/promotion of urine diversion toilets.

- Water harvesting: CSOs work with household members to develop ways of retaining rainfall from roofs and yards for home and garden use, and spread related practices.

- Community gardening: CSOs locate space and train and organize community members to plant gardens for collective food production.

- Community kitchens: NGOs or churches establish kitchen space for collective food preservation, processing and cooking and for feeding vulnerable community members and buffering time pressures for women.

- Leadership training: CSOs work with government and watershed committee officials to develop inclusivity training and confidencebuilding workshops for women, to welcome and facilitate their participation in water governance institutions.

- Watershed learning circles: Watershed committees, assisted by CSOs, bring together key civil society groups from throughout the watershed (e.g. journalists, teachers, artists, government officials) to discuss and develop needed action programs on water-related issues.

- Maputo university environmental education students are working with intermediate school youth on after-school activities related to climate change. Participation by parents and teachers is also welcome. The bulk of all participants are women.

\section{Conclusion}

Engaging women is fundamentally important for durable climate change adaptation, particularly during environmental crises. Women possess incomparable knowledge of local ecological and water conditions due to gendered roles and responsibilities 
and this knowledge must be shared and utilized in local, national and international negotiations and decision-making processes for reasons of both justice and efficiency. Democratic mediation of equity conflicts related to water, and sustainable long-term management of water resources, are only possible through public participation.

Community-based, 'people-centred' approaches to climate change are needed in order to develop adaptation strategies which address social and gender inequalities and allow women to serve as active agents of change in their communities. "Past history shows that the poor and vulnerable do not get a fair share of resources unless they can mobilize effectively and there is parallel pressure on the powerful to make decisions in favour of the many, not the few. In the context of the climate change negotiations, this means making sure that the voices of ordinary Africans-women, men, young, old, farmers and slum dwellers-are heard loud and clear as the policies and institutions for addressing the most challenging of global problems are developed" (Toulmin, 2010: 152).

Climate change does not happen in a vacuum-in developing countries existing developmental challenges, such as poverty, gender and structural inequalities, and inadequate infrastructure further aggravate the vulnerability of the poor, and women in particular. We must recognize and address the many interactions between climate change and existing gender inequalities, in order to reduce the likelihood that the livelihoods of already vulnerable and marginalized people will be significantly worsened by climate change. This paper has identified and summarized ways of engaging women which have proven successful in local work in particular places, and may help to generate related strategies in other places. Starting in local communities, with women's leadership, and communicating with others who are also facing similar challenges, is a promising way forward.

\section{References}

Anisfeld, S.C., 2010. Water Resources. Island Press, Washington, DC.

Bied-Charreton, M., 2008. Integrating the Combat Against Desertification and Land Degradation into Negotiations on Climate Change: A Winning Strategy. UNCCD. http://www.unccd.int/science/docs/non_paper_desertif_Climate_eng.pdf (accessed 04.05.11)

Blackden, C.M., Wodon, Q. (Eds.), 2006. Gender, Time Use, and Poverty in SubSaharan Africa. World Bank Working Paper No. 73. The World Bank, Washington, DC.

CIDA, 2002. Gender Equality And Climate Change: Why Consider Gender Equality When Taking Action on Climate Change? Canadian International Development Agency, Ottawa. Available at: http://www.acdi-cida.gc.ca/INET/IMAGES.NSF/ vLUImages/Climate\%20change3/\$file/Gender-2.pdf (accessed 06.10.11).

De Marchi, B., Funtowicz, S.O., Lo Cascio, S., Munda, G., 2000. Combining participative and institutional approaches with multicriteria evaluation. an empirical study for water issues in Troina, Sicily. Ecological Economics 34, 267-282.

Dessai, S., Adger, W.N., Hulme, M., Turnpenny, J., Kohler, J., Warren, R., 2004. Defining and experiencing dangerous climate change. Climatic Change 64, 11-25. Kluwer Academic Publishers, Netherlands.

Ensor, J., Berger, R. (Eds.), 2009. Understanding Climate Change Adaptation: Lessons from Community-Based Approaches. Practical Action Publishing, Bourton on Dunsmore, UK.
Faucheux, Sylvie, Hue, Christelle, 2001. From irreversibility to participation: towards a participatory foresight for the governance of collective environmental risks. Journal of Hazardous Materials 86, 223-243.

Gregory, Robin, Slovic, Paul, 1997. A constructive approach to environmental valuation. Ecological Economics 21, 175-181.

Hinchcliffe, F., et al., 1999. Fertile Ground: The Impacts of Participatory Watershed Management. Earthscan/IT Publications, London.

Holland, Alan, 1997. The foundations of environmental decision-making. International Journal of Environment and Pollution 7 (4), 483-495.

Intergovernmental Panel on Climate Change, 2007. Climate Change 2007: Synthesis Report. Available at: http://www.ipcc.ch (accessed 04.05.11).

Kapoor, Ilan, 2008. The Post-Colonial Politics of Development. Routledge, London/ New York.

Kindon, S., Pain, R., Kesby, M., 2008. Participatory Action Research. International Encyclopedia of Human Geography. Elsevier, Amsterdam/London, pp 90-95.

Kothari, Uma, 2001. Power, knowledge and social control in participatory development. In: Cooke, Bill, Kothari, Uma (Eds.), Participation: The New Tyranny? Zed Books, London.

Lim, Bo, Spanger-Siegfried, Erika, 2004. Adaptation Policy Frameworks for Climate Change: Developing Strategies, Policies and Measures. Cambridge University Press and United Nations Development Programme, Cambridge, UK.

Meyer, W.B., Butzer, K.W. Downing T.E., Turner II, B.L, Wenzel, G.W., Wescoat, J.L 1998. Reasoning by analogy. In: Rayner, S., Malone, E.L. (Eds.), Human Choice and Climate Change. The Tools for Policy Analysis, vol. 3. Battelle Press, Washington, D.C, pp. 217-289.

Mirza, M.M.Q., 2003. Climate change and extreme weather events: can developing countries adapt? Climate Policy 3 (3), 233-248.

Moraes, A., Perkins, P.E., 2009. Etica, Genero e Classe Social na Politíca Participativa de Agua. In: Gislene Aparecida dos Santos (Ed.), Etica, Pesquisa e Políticas Publicas. Editora Rubio, São Paulo, Brazil, pp. 107-122.

Neumayer, E., Plümper, T., September 2007. Catastrophic events on the gender gap in life expectancy, 1981-2002. Annals of the Association of American Geographers 97 (3), 551-566. doi:10.1111/j.1467-8306.2007.00563.x.

Paavola, J., Adger, W.N., Huq, S., 2006. Multifaceted justice in adaptation to climate change. In: Adger, W.N., et al. (Eds.), Fairness in Adaptation to Climate Change. MIT Press, Cambridge, MA/London, UK, pp. 263-278.

Parry, et al., 2007. p. 452, drawing from Brooks, N., Adger, W.N., Kelly, P.M., 2005. The determinants of vulnerability and adaptive capacity at the national leve and the implications for adaptation. Global Environmental Change 15 (2), 151-163.

Perkins, Patricia E., 2003. Public participation in ecological valuation: how policies can help it happen. Paper Presented at the Conference of the Canadian Society for Ecological Economics (CANSEE), Jasper, Alberta, October 16-19.

Perkins, P.E., 2004. Participation and watershed management: experiences from Brazil. Paper Presented at the Conference of the International Society for Ecological Economics (ISEE), Montreal, Canada, July 10-14.

Sagoff, M., 1998. Aggregation and deliberation in valuing environmental public goods: a look beyond contingent pricing. Ecological Economics 24 $213-230$.

Sister Watersheds, 2008. Project website: www.yorku.ca/siswater (accessed 11.10.11).

Smit, Barry, Wandel, Johanna, 2006. Adaptation, adaptive capacity and vulnerability. Global Environmental Change 16, 282-292.

Terry, G. (Ed.), 2009. Climate Change and Gender Justice. Practical Action Publishing in Association with Oxfam GB, Rugby, UK.

Toulmin, C., 2010. Climate Change in Africa. Zed Books, London/New York.

United Nation Human Settlements Program (UN Habitat), 2010. Climate Change Assessment for Maputo, Mozambique. Cities and Climate Change Initiative. Nairobi, Kenya. Available at: www.unhabitat.org/pmss/getElectronicVersion. aspx?nr=2977\&;alt=1 (accessed 05.05.11).

van den Hove, Sybille, 2000. Participatory approaches to environmental policymaking: the European commission climate policy process as a case study. Ecological Economics 33, 457-472.

Wilson, Matthew A., Howarth, R.B., 2002. Discourse-based valuation of ecosystem services: establishing fair outcomes through group deliberation. Ecological Economics 41, 431-443. 